\title{
Teaching Technology Usage in the ENT Medical Subdomain via a Flipped Classroom Approach
}

\author{
https://doi.org/10.3991/ijac.v11i1.9105 \\ Walter Koch ${ }^{1}$, Jochen Schachenreiter ${ }^{2}$, Klaus Vogt ${ }^{3}$, Gerda Koch ${ }^{4}$ and Wolfgang Göderle ${ }^{5}$ \\ ${ }^{1}$ Steinbeis Transfer Center for Information Management, Medical and Cultural Heritage Informatics, Graz, Austria \\ ${ }^{2}$ Medical Practice Schachenreiter, Graz, Austria \\ ${ }^{3}$ University of Latvia, Riga/Center of Experimental Medicine, Latvia \\ ${ }^{4}$ AIT Angewandte Informationstechnik Forschungsgesellschaft mbH, Graz, Austria \\ ${ }^{5}$ Karl-Franzens-University/History Department, Graz, Austria
}

\begin{abstract}
The flipped classroom approach is supporting a continuous interaction of students and instructors via online communication and strengthens the ability to solve problems by self-organization. This is especially important in medical domains, like the one of ENT-Head/Neck (ENT: Ear-Nose-Throat) surgeries and treatment. Surgical corrections of the nasal airways, like FESS (Functional Endoscopy Sinus Surgery) or in the field of plastic surgery, are the second frequent surgical interventions in otorhinolaryngology. They have to be prepared very carefully and airflow simulation with Computational Fluid Dynamics (CFD) is gaining importance for diagnostics here. New in silico procedures, like imaging, 3D modelling, CFD simulation and analysis, are to be part of a standard clinical pathway in the ENT domain in the near future. The project Rhinodiagnost.eu for instance will extend the morphological diagnostics by detailed functional analysis, i.e. the visualization of the nasal air stream and the physical analysis of its energetic. In order to train ENT specialists on the new diagnostic aids Rhinodiagnost.eu will provide flipped classroom online lessons using the tool "Mediathread" of the Columbia University, as learning environment.
\end{abstract}

Index Terms-Flipped Classroom, Ear-Nose-Throat Treatment, CFD simulation, 3D modelling.

\section{INTRODUCTION}

"Flipped classroom", a type of blended learning, is a preferred method for knowledge transfer to students and among all kind of members within institutions. Using this method the instructor adopts the role of a coach and encourages the learners to interact and to contribute content themselves. This method strengthens the ability to solve problems by self-organization [1] which is especially important in medical domains, like the one of ENT-Head/Neck (ENT: Ear-Nose-Throat) surgeries and treatment. In this medical field new in silico procedures, like imaging, 3D modelling, CFD (Computational Fluid Dynamics) simulation and analysis, are to be part of a standard clinical pathway in the ENT domain in the near future. Surgical corrections of the nasal airways, like FESS (Functional Endoscopy Sinus Surgery) or in the field of plastic surgery, are the second frequent surgical interventions in otorhinolaryngology. They have to be prepared very carefully and airflow simulation via CFD is gaining importance for diagnostics here. The project Rhinodiagnost.eu for instance will extend the morphological diagnostics by detailed functional analysis, i.e. the visualization of the nasal airflow and the physical analysis of its energetic. The visualization and simulation of airflows from the nostrils to the nasal pharynx afford a precise and high quality 3D reconstruction of the nasal cavities. And the successive validation and interpretation of CFD simulation results is a challenge for non CFD specialists. Therefore Rhinodiagnost.eu project will use the flipped classroom online tool Mediathread, developed by the Columbia University, as learning environment. With Mediathread "compositions" for explaining specific concepts like: image processing, 3D modelling, CFD simulations, definition and processing of clinical pathways, are published and "assignments" to students, asking to elaborate on various topics may be issued. The continuous interaction of students and instructors via Mediathread will support medical technical competence development according to the knowledge maturity model.

\section{A. New Learning Technologies}

With the introduction of online courses and networked information services higher education and workplace learning has changed tremendously. Digital technologies have gained huge influence on how we learn and how we obtain information. A new emphasis is put on the benefits of active (online) learner's participation. Collective content development and learning in networked communities is seen as a means to filter out the right content for our needs from the mass of information provided globally. Open (online) communication with team members and learning partners creates synergies and new insights into issues making it easier to create innovative solutions, creative alternatives, and new goals.

In modern learning environments, the learners move to the center and the choice of learning resources is closely related to the professional context. Within virtual learning platforms joint knowledge bases are built and the participatory contributions of learners and trainers can be clearly arranged and stored and additionally be kept ready for repeated training. This makes it easier to later build upon existing content, in order to expand the wealth of experience, the knowledge base. Preparing Micro learning compositions, which implies packing the learning content into small lessons, provides the advantage of rapid adaptability and structuring of the knowledge. That way, the learner can consume the content quickly and flexibly [2].

Studies have shown that up to $80 \%$ of activity-based knowledge is acquired through informal learning, such as 
questioning, observing or trying out [3]. Collaborative learning environments support this form of competence building as the focus shifts from the teacher to the learner and knowledge is generated collectively through interaction and the learning of teams [4].

\section{NEW TECHNOLOGIES FOR THE ENT MEDICAL SUBDOMAIN}

\section{A. Additional Diagnostic Tools for ENT Diagnostics}

About $11 \%$ of the European population suffers from an obstruction of nasal breathing or an inflammation of the nasal sinuses [5]. For patients affected the quality of life can be severely limited. In Germany, Austria and Switzerland, more than 100,000 surgeries on the nose or the nasal sinuses are carried out annually. In the US, more than 500,000 nasal and sino-nasal surgeries per year are performed [6]. But the present diagnosis of nasal function is not accurate enough, in order to provide always a clearly verifiable indication for nasal surgeries.

Computational Fluid Dynamics (CFD) as a methodology to visualize the airflow in nasal and paranasal sinuses has been topic of many scientific papers during the last decades. To know and see whether airflow enters a paranasal sinus or not is important for the ENT surgeon preparing a surgery in a paranasal sinus. But integrating CFD-Simulation into a day to day clinical operation is still an open issue due to the complexity and multidisciplinarity of this approach. The involvement of highly experienced medical experts, fluid dynamic experts, as well as informatics experts - only to name a few - in combination with expensive computer hardware (HPC High Performance Computing) has made it nearly impossible in the past to make CFD-simulations available for the established ENT-specialist.

Current research projects try to change this situation and put a focus on the validation of CFD results and on the integration of different methodologies (3D models, CFD simulations) into a virtual surgery device for preparing ENT surgeries. They also aim to include 3D visualization and CFD simulation into the standard clinical pathway for ENT treatment. In September 2017 the European Union-funded project Rhinodiagnost (www.rhinodiagnost.eu) started. The project will establish coordinated morphological and functional diagnostics services for ENT physicians [7]. New, additional decision aids, such as $3 \mathrm{D}$ models and flow simulations, shall be offered to ENT physicians and radiologists. Project partners within Rhinodiagnost.eu are renowned research centers like the Technical University of Aachen, the Supercomputing Center Juelich, and several privately owned companies in the information and medicaltechnical sector. Rhinodiagnost.eu will provide a network of easy accessible and low-cost service points for these diagnostic services and targets to introduce these technologies as standard means for ENT diagnostics. The supplied information surplus will allow surgeons and practitioners that are trained on the new technologies to improve patient-individual operation and treatment planning. In the long run the use of the services should raise the success rate of surgeries and of treatments.

\section{Teaching Technology Usage for ENT SPECIALISTS}

\section{A. Implementing a Flipped Classroom Approach}

Training for highly qualified occupations needs to focus to a great extent on strengthening the ability to solve problems by self-organization and enabling the learner to recognize connections between subjects, ideas and concepts. Competence development is basically fostered by the assessment of observable behavior and action [8]. Collaborative online learning environments that put the focus on the learner and the knowledge creation through the interactive learning of teams support these training principles [9]. In a flipped classroom environment the teacher adopts the role of a trainer or coach [10] and the self-organized interaction between the learners or trainees is the central source of knowledge transfer. Knowledge is mostly assembled via social exchange, the guidance of a tutor and the delivery of self-created content. Therefore, an online platform for flipped classroom learning should support the creation of structured micro learning units, the integration of a wide variety of multimedia content (video, audio, images, texts etc.), the collection and management of external resources, the assignment of tasks, and should include easy-to-use functionalities for online cooperation, communication, discussion and feedback.

The Rhinodiagnost.eu project looked for a tool that would not just offer a comprehensive learning management or content management system, but rather support the participatory design and documentation of subject areas. Evaluation of various platforms resulted in the adoption of the open source platform Mediathread (http://mediathread.columbia.edu/) for Rhinodiagnost.eu purposes. Mediathread has been developed by the Columbia Center for New Media Teaching and Learning at Columbia University since 2010 and is used in a variety of courses, including at other American universities. The focus of Mediathread is on providing a platform for the preparation, management and analysis of online multimedia content. The tool works very well with a small, focused scholarly community or seminar, supporting connections, open access, and networked learning. The platform enables the linking and integration of content from various external media platforms such as YouTube, Flickr, the Internet Archive, Vimeo, Wikimedia Commons, Pinterest or Kaltura. Using Mediathread the content can be further edited, annotated, organized and embedded in texts. It is possible to link descriptions to external content and enrich them. Instructors and coaches can coordinate respective threads. The tool also supports the creation of short assignments or questions that learners and team members need to work on and contribute online. Thus, step by step, a knowledge base is built cooperatively.

Mediathread does not upload multimedia data (videos, pictures, audios) to the system, but simply refers to the content and embeds it in the courses of the platform. Doing this a student can contribute information of his or her own interest into a lesson. There, the content can be further distributed, annotated, tailored and referenced in the discussion and knowledge contributions. In addition, it is also possible for administrators or tutors to enable an upload function for existing local multimedia content. 
For the ENT case the tool Mediathread provides the possibility of elaborating "compositions" which can either explain a specific concept like: image processing, 3D modelling, CFD simulations, definition and processing of clinical pathways, etc. or present an "assignment" to a student, asking to elaborate on various topics. Through the continuous interaction of students and instructors the Mediathread platform is enhanced in an iterative process.

\section{B. ENT Training with Mediathread}

Research in Rhiodiagnost.eu and other related projects [11] has brought forward that a comprehensive diagnostic tool-kit for ENT practitioners and radiologists ought to include visualization of the nasal cavities (using 3D modelling), the execution of CFD-simulation, and in special cases even the print out of 3D models of pathological regions of interest. The 3D mesh generated from the CT DICOM-images allows the doctors and surgeons to view the diseased areas from all perspectives, making it possible to virtually zoom into the tiniest regions and holes. Hence, the mesh of the paranasal sinuses is an important aid for the planning and preparation of, for example, Functional Endoscopic Sinus Surgery (FESS) and can be used for education and training on FESS. When conducting a Functional Endoscopic Sinus Surgery an endoscope, a thin fiber-optic tube, is used to improve ventilation and drainage and to remove polyps. With the endoscope and specialized tools the surgeon removes unusual and obstructive tissues through the nostrils. This technique has now been used for several decades in treating sino-nasal conditions and the extent of each surgery depends on the severity of the disease and the surgeon's individual practice.

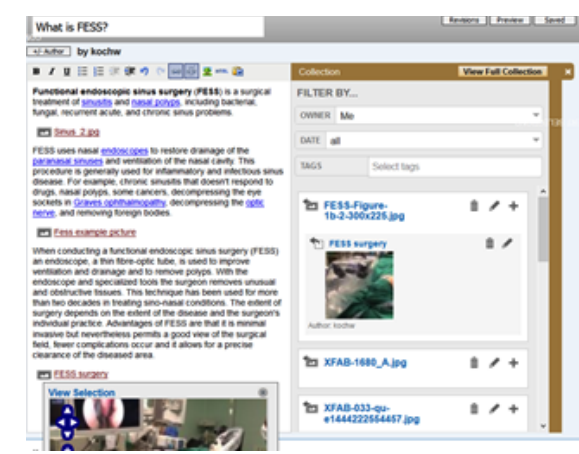

Figure 1. Preparation of a composition on FESS

Fig. 1 shows the composition panel. Left the information texts are entered which are enriched with media items selected from the media "Collection" list on the right-hand side. Media used to enrich the written information may be annotated and in extracts selected for the course.

For making the adequate diagnosis of Chronic rhinosinusitis (CRS) a check-up is carried out by the ENTHead/Neck surgery specialist. In addition to the anamnesis, a nose endoscopy and a spiral Computed Tomography (CT) of the paranasal sinuses is done, which should preferably be carried out in an inflammation-free interval. The extent of shading of the paranasal sinuses in the CT and the anatomical relationships determine the severity of CRS [16]. However, the 2-dimensional images of the conventional CT examination of the paranasal sinuses merely give an idea of the ventilation of the sinuses. But current developments in the field of numerical flow mechanics and high-performance calculations are permitting patient-individual computerassisted flow predictions that can help to detect and limit the anatomical location of pathologies. A CFD simulation of the nose and the paranasal sinuses can be performed [12], [13]. With this method, the inner nose can be virtually traversed, and the slight flows in the area of the paranasal sinuses, especially the very narrow passages, can be visualized [14], [15]. The main advantage for the radiologist and the ENT-Head-neck surgeon is that additionally to the static CT-examination the CFD will show the dynamic function of the ventilation in the nasal cavity and the paranasal sinuses. This improves both: sensitivity and specificity in the assessment of pathologies such as, for example. a Chronic rhinosinusitis (CRS).

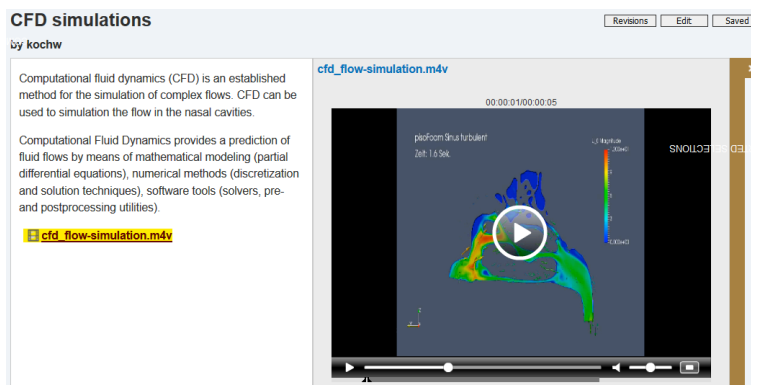

Figure 2. Preparation of a composition on FESS

Fig. 2 shows part of a composition on the basic principles of CFD attached with a video on the simulation of a nasal airflow.

In order to correctly use and interpret the results of the 3D meshes and the CFD simulation doctors and surgeons need to be trained on these new technologies. Surgeons shall be able to use both technologies to improve surgery planning and to simulate possible post-surgery scenarios. For that it is important to know what the CFD simulation tells about the airflow, and how to use and interpret the 3D mesh generated out of the DICOM images. Fig. 3 shows the micro learning unit on 3D meshes where a short introduction on image-based meshing from computed tomography data for medical specialists is provided.
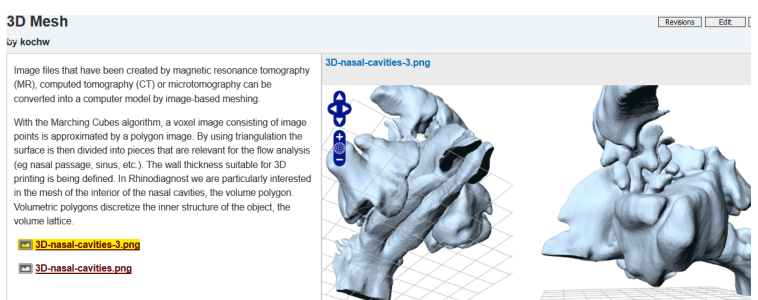

Figure 3. Composition on 3D meshing

CFD and 3D meshes render diagnostics more precisely and both technologies can also be applied in training, for virtual surgery or for producing $3 \mathrm{D}$ printed training models for surgeons-to-be. $3 \mathrm{D}$ printing provides important additional information for difficult surgeries in selected 
regions of interest [17]. Fig. 4 depicts parts of a composition on this topic.
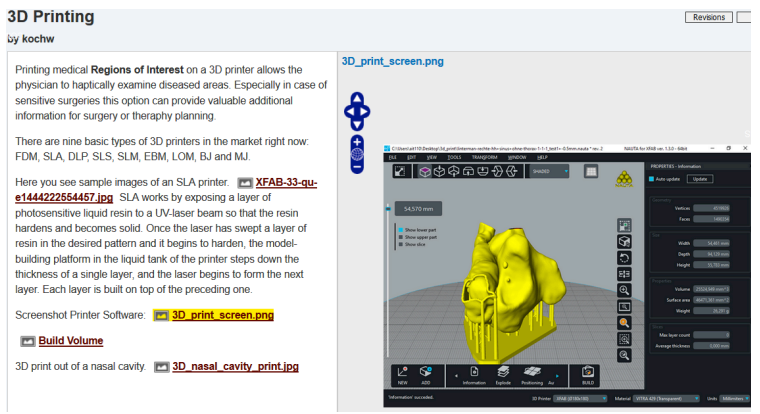

Figure 4. Introduction to $3 \mathrm{D}$ printing

500.000 FESS-surgeries are taking place every year in the US only, an amount of about 2.000 surgeries per working day or 300 per working hour is a reasonable figure [18], [19], [20]. Therefore, it is important to optimize the different activities in the surgery preparation workflow. Standard clinical pathways reduce variations in practice and align decisions with evidence-based medicine, operational efficiency, and quality. The Object Management Group (http://www.omg.org/), being an international, open membership, not-for-profit technology standards consortium, has started in 2016 an initiative, the "Health BPM Pilot", to standardize the description of clinical procedures. In October 2017 a draft version of the "Field Guide to Shareable Clinical Pathways" was issued. The Health BPM Pilot strongly advocates the use of standards like the Business Process Modelling and Notation (BPMN), the Decision Management and Notation (DMN), or the Case Management Model and Notation (CMMN) for the design process of clinical pathways. It is important that ENT specialists are able to read business process models conceptualized with standard notations in order to contribute to the clinical pathway discussion. Fig. 5 shows a Mediathread discussion based on an assignment on standard modelling notations.

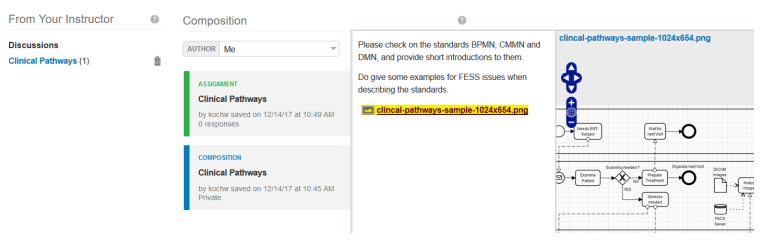

Figure 5. Assigning and discussing the use of standard notations

The first draft version of the Mediathread training course created by Rhinodiagnost.eu focuses on basic knowledge transfer for Computational Fluid Dynamics, 3D meshing and 3D printing for ENT specialists. Medical practitioners and students should get a basic understanding of these technologies and how they can be used in ENT diagnostics. As new technologies are further intruding into all work areas the course will be constantly adapted and enhanced. Finally, the course platform should provide a growing source of knowledge for ENT experts and a means for international discussion and sharing of experiences with the new diagnostic tools. Currently, a new composition on machine learning and convolutional neural networks is being set up. Since the radio source of the CT is operated with the weakest possible intensity, for the benefit of the patient, not all structures in the CT images are optimally recorded. Therefore the images need to be re-worked in order to serve as proper basis for the $3 \mathrm{D}$ visualization and mesh generation. This happens either via a time-consuming manual post processing processes or with the help of machine learning and convolutional neural networks (CNN) [21, 22]. The $\mathrm{CNN}$ can be trained to detect automatically whether a point of the CT scan (DICOM image) is located inside or outside of a nasal (or paranasal) sinus. This will lead in the long run not only to quick image segmentation and $3 \mathrm{D}$ processing but also to a classification indicating the pathological condition of a nasal or paranasal sinus.

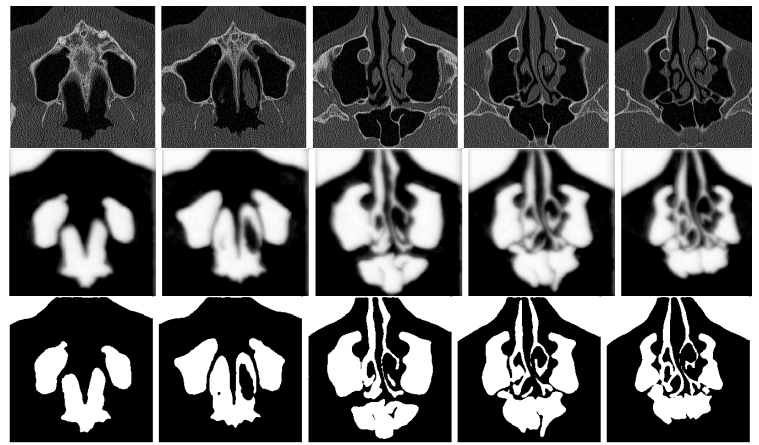

Figure 6. CT images and $\mathrm{CNN}$ supported segmentation

\section{CONCLUSION}

Novel diagnostic tools using CFD simulation and 3D visualization will be provided to ENT specialists and radiologists in the near future. These tools can be offered via rapid networks to ENT practitioners and radiologists. But students and doctors need to be trained to work with the new tools and to correctly assess their diagnostic input. The Rhinodiganost.eu project uses the Mediathread platform as a flipped classroom environment to offer training for the Rhinodiagnost morphological and functional ENT diagnostic services. The courses teach students and doctors how to use CFD simulations, 3D meshing or $3 \mathrm{D}$ printing, and introduce into topics like business process modelling for clinical pathways or machine learning. All courses offer introductory online compositions, assignments for participants, media material and the possibility to interact with a tutor or coach. Trainees may actively shape and contribute online to a joint knowledge base thus strengthening their ability of self-organization, networked collaboration and digital competence.

\section{REFERENCES}

[1] G. Siemens, "Connectivism: A Learning Theory for the Digital Age," in International Journal of Instructional Technology and Distance Learning, vol. 2, no. 1, pp. 3-10, 2005.

[2] G. Siemens, "Connectivism: Creating a Learning Ecology in Distributed Environments," in: Didactics of microlearning. Concepts, discourses and examples, Hug, Theo (Eds.), 2007, pp. 53-68. 
[3] G. Attwell, "Personal Learning Environments - the future of eLearning?," in eLearning Papers, vol. 2, no. 1, 2007.

[4] P. M. Senge, "The Fifth Discipline: The Art \& Practice of The Learning Organization." Crown Publishing Group, 2010.

[5] D. Hastan, et al., "Chronic Rhinosinusitis in Europe - an underestimated disease. A GA ${ }^{2}$ LEN study", in Allergy, vol 66, no. 9, 2011. https://doi.org/10.1111/j.1398-9995.2011.02646.x

[6] N. Bhattacharyya, "Ambulatory sinus and nasal surgery in the United States: demographics and perioperative outcomes", in Laryngoscope, vol. 120, no. 3, pp. 635-8, 2010. https://doi.org/10.1002/lary.20777

[7] A. Lintermann, J.H. Göbbert, K. Vogt, W. Koch, and A. Hetzel, "Rhinodiagnost - Morphological and functional precision diagnostics of nasal cavities", in InSiDE, Innovative Supercomputing in Deutschland, vol. 15, no. 2, pp. 106-109, 2017.

[8] A. Bolder, "Arbeit, Qualifikation und Kompetenzen," in Handbuch Bildungsforschung. 2. Ed., Tippelt, Rudolf/Schmidt, Bernhard, Hrsg., 2009, pp. 813-843. https://doi.org/10.1007/9783-531-91831-0 43

[9] H. Lee, C. J. Bonk, "Collaborative Learning in the Workplace. Practical Issues and Concerns," in International Journal of Advanced Corporate Learning (iJAC), vol. 7, no. 2, p. 10, 2014. https://doi.org/10.3991/ijac.v7i2.3850

[10] F. Böhm, „Der Tele-Tutor. Betreuung Lehrender und Lernender im virtuellen Raum,“ VS Verlag für Sozialwissenschaften, GWV Fachverlage GmbH Wiesbaden, 2006.

[11] J. Schachenreiter, G. Ranner, W. Koch, R. Jakse, and M. Wu, "Verification of the Ventilation of the Paranasal Sinuses using Computational Fluid Dynamics (CFD)," unpublished.

[12] S. K. Kim, Y. Na, J.-I. Kim, and S.-K. Chung, "Patient specific CFD models of nasal airflow: Overview of methods and challenges," in Journal of Biomechanics, Special Issue: Biofluid Mechanics, vol. 46, no. 2, Jan. 2013, pp. 299-306.

[13] D. J. Doorly, D. J. Taylor, A. M. Gambaruto, R. C. Schroter, and N. Tolley, "Nasal Architecture: Form and Flow," in Philosophical Transactions of the Royal Society of London A: Mathematical, Physical and Engineering Sciences, vol. 366, no. 1879, Sep. 2008, pp. 3225-46.

[14] S. Zachow, A. Steinmann, T. Hildebrandt, R. Weber, and W. Heppt, "CFD simulation of nasal airflow: towards treatment planning for functional rhinosurgery," in International Journal of Computer Assisted Radiology and Surgery, Jun. 2006, pp. 165167.

[15] R. Mösges, B. Büchner, M. Kleiner, R. Freitas, I. Hörschler, and W. Schröder, "Computational fluid dynamics analysis of nasal flow," in B-ENT, vol. 6, no. 3, Jan. 2010, pp. 161-165.

[16] W. J. Fokkens, V. J. Lund, J. Mullol, C. Bachert, I. Alobid, F. Baroody et al., "European Position Paper on Rhinosinusitis and Nasal Polyps 2012," in Rhinology, vol. 50, sup. 23, Mar. 2012, pp. 201-207.

[17] K.K. VanKoevering, K.M. Malloy, "Emerging Role of ThreeDimensional Printing in Simulation in Otolaryngology," in Simulation in Otolaryngology, Otolaryngologic Clinics of North
Amerika, vol. 50, no. 5, Oct. 2017, pp. 98-110. https://doi.org/10.1016/j.otc.2017.05.006

[18] K. A. Smith, R. R. Orlandi, and L. Rudmik. "Cost of adult chronic rhinosinusitis: a systematic review," in The Laryngoscope, vol. 125, no. 7, Jan. 2015, pp. 1547-1556. https://doi.org/10.1002/lary. 25180

[19] W. Fokkens, V. Lund, C. Bachert, P. Clement, P. Helllings, M Holmstrom et al., "EAACI Position Paper on Rhinosinusitis and Nasal Polyps Executive Summary," in Allergy, vol. 60, no. 5, May 2005, pp. 583-601.

[20] M. A. Pynnonen, and M. M. Davis, "Extent of sinus surgery, 2000 to 2009: A population-based study," in The Laryngoscope, vol. 124, no. 4, Apr. 2014, pp. 820-825. https://doi.org/10.1002/lary. 24335

[21] S. Wang, and R. M. Summers, "Machine Learning and Radiology," in Medical Image Analysis, vol. 16, no. 5, Jul. 2012 , pp. 933-51. https://doi.org/10.1016/j.media.2012.02.005

[22] J.-G. Lee, S. Jun, Y.-W. Cho, H. Lee, G. Bae Kim, J. Beom Seo, and N. Kim, "Deep Learning in Medical Imaging: General Overview," in Korean Journal of Radiology, vol. 18, no. 4, Aug. 2017, pp. 570-84. https://doi.org/10.3348/kjr.2017.18.4.570

\section{AUTHORS}

Univ.Prof.Dr. Walter Koch, is with Steinbeis Transfer Center for Information Management, Medical and Cultural Heritage Informatics, Klosterwiesgasse 32/1, A8010 Graz, Austria (e-mail: walter.koch@stw.de).

Dr.med. Jochen Schachenreiter, is with Medical Practice Schachenreiter, Elisabethstrasse 81, A-8010 Graz, Austria (e-mail: ordination@schachenreiter.at).

Univ.Prof.Dr. Klaus Vogt, MD, DDS, is with University of Latvia, Center of Experimental Medicine, Raiņa bulvāris 19, Centra rajons, Rīga, LV-1586, Lettland (e-mail: rhinovogt@t-online.de).

Mag. Gerda Koch MBA, is with AIT Angewandte Informationstechnik Forschungsgesellschaft $\mathrm{mbH}$, Klosterwiesgasse 32/1, A-8010 Graz, Austria (e-mail: kochg@ait.co.at).

Mag.Dr. Wolfgang Göderle, is with Karl-FranzensUniversity Graz, Attemsgasse 8/IV, A-8010 Graz, Austria (e-mail: wolfgang.goederle@uni-graz.at).

Manuscript received 15 March 2018. This work is supported in part by the EU-Programme COIN/IraSME under Grant 861510.

Published as submitted by the author(s). 